\title{
Relato de Experiência de uma Psicóloga em um CAPS, Mato Grosso, Brasil
}

\author{
Virgínia de Albuquerque Mota \\ Ministério da Saúde, \\ Cuiabá, MT, Brasil.
}

\author{
Ilze Maria Gonçalves da Costa \\ Universidade de Cuiabá, \\ Cuiabá, MT, Brasil.
}

Resumo: As políticas de estado voltadas para a saúde mental no Brasil desenvolveram-se no século XX e foram marcadas sucessivamente ao longo deste período pelos modelos asilares e de tratamento moral. A partir da segunda metade do século XX, a Psicologia é instituída como ciência e profissão para se enquadrar à proposta de tratamento moral e ajustamento social dos considerados "desviantes". Com o advento da reformulação legal e normativa do modelo de assistência à saúde, fruto da Constituição de 1988 e das Leis no 8.080 e nº 8.142 de 1990, um novo campo de atuação e de práticas se coloca para o profissional da Psicologia, ainda que a formação permanecesse a mesma. Este artigo é o relato de experiência de uma psicóloga em um serviço de saúde mental no interior do estado de Mato Grosso, entre 2007 e 2009, que busca refletir sobre a formação profissional e a construção da prática profissional na busca da efetivação desse novo modelo de assistência à saúde mental, voltado para a saúde e a reabilitação psicossocial. Verificou-se que, apesar da implantação do serviço ter se dado de forma verticalizada, uma nova concepção de saúde mental foi construída, em um movimento de reconstrução do significado da finalidade daquela unidade de saúde. Conclui-se que os serviços de atenção à saúde mental são espaços formativos de reconstrução da prática profissional e de cidadania.

Palavras-chave: Prática Profissional, Psicologia, Saúde Mental.

\section{Experience Report of a Psychologist at a CAPS, Mato Grosso, Brazil}

\begin{abstract}
State policies aimed at mental health in Brazil developed in the twentieth century, and were marked successively over this period by asylum and moral treatment models. From the second half of the twentieth century, psychology is instituted as science and profession to fit the proposal of moral treatment and social adjustment of those considered "deviant." The advent of the legal and normative reformulation of the health care model, as a result of the 1988 Constitution and Laws 8,080 and 8,142/1990, a new field of practice and practice is put to the psychology professional, even though the formation remained the same. This article is the experience report of a psychologist in a mental health service in the state of Mato Grosso, between 2007 and 2009, which seeks to reflect on professional training and the construction of professional practice in the search for the effectiveness of this new model of mental health care, focused on health and psychosocial rehabilitation. It was verified that although the service was implemented vertically, a new conception of mental health was built, in a movement to reconstruct the meaning of the purpose of that health unit. It is concluded that mental health services are formative spaces for the reconstruction of professional practice and citizenship.
\end{abstract}

Keywords: Professional Practice, Psychology, Mental Health. 


\title{
Relato de Experiencia de una Psicóloga en un CAPS, Mato Grosso, Brasil
}

\begin{abstract}
Resumen: Las políticas de Estado orientadas a la salud mental en Brasil se desarrollaron en el siglo XX, y fueron marcadas sucesivamente a lo largo de este período por los modelos asilares y de tratamiento moral. A partir de la segunda mitad del siglo XX, la Psicología es instituida como ciencia y profesión para encuadrarse a la propuesta de tratamiento moral y ajuste social de los considerados "desviantes". El advenimiento de la reformulación legal y normativa del modelo de asistencia a la salud, fruto de la Constitución de 1988 y de las Leyes no 8.080 y 8.142/1990, un nuevo campo de actuación y de prácticas se colocan para el profesional de la psicología, La formación permaneciera igual. Este artículo es el relato de experiencia de una psicóloga en un servicio de salud mental en el interior del Estado de Mato Grosso, entre 2007 y 2009, que busca reflexionar sobre la formación profesional y la construcción de la práctica profesional en la búsqueda de la efectividad de este nuevo modelo de Asistencia a la salud mental, orientado a la salud ya la rehabilitación psicosocial. Se comprobó que a pesar de la implantación del servicio se dio de forma verticalizada, una nueva concepción de salud mental fue construida, en un movimiento de reconstrucción del significado de la finalidad de aquella unidad de salud. Se concluye que los servicios de atención a la salud mental son espacios formativos de reconstrucción de la práctica profesional y de ciudadanía.
\end{abstract}

Palabras clave: Practica Profissional, Psicologia, Salud Mental.

\section{Introdução}

O marco institucional da assistência à saúde mental no Brasil foi a inauguração do Hospício Dom Pedro II, em 1852, no Rio de Janeiro, afastado do centro da cidade e referência para os pacientes de todo território nacional. Esta unidade logo atingiu sua lotação máxima e serviu de modelo para a criação de outros asilos de características similares. Estas instituições destinavam-se à remoção e à exclusão de pessoas que interferiam na ordem social, em nome da segurança das outras pessoas e do patrimônio, e à indicação clínica para o tratamento (Resende, 1994).

No final do século XIX e início do século XX, as transformações sociais e econômicas relacionadas ao êxodo rural e o processo de industrialização dos grandes centros levaram o Estado a adotar medidas de proteção social dos trabalhadores através da criação dos Institutos de Aposentadorias e Pensões, que tinham a função de preservar a força de trabalho.

Neste contexto histórico, os asilos começam a dar lugar aos Hospitais, e a psiquiatria empírica era substituída por uma psiquiatria científica, fundamentada na psiquiatria francesa de Pinel, cujo eixo central era o tratamento moral. Até a metade do século XX, no entanto, tem-se registro de uma proliferação de asilos manicomiais, que serviam mais à manutenção da ordem social e que eram caracterizados pela superlotação, deficiência de pessoal, maus-tratos, péssimas condições prediais e de infraestrutura (Resende, 1994).

Neste mesmo contexto histórico, a Psicologia é instituída como ciência e profissão no Brasil pela Lei Federal no 4.119, de 27/08/1962 (Brasil, 1962) e regulamentada pelo Decreto no 53.464, de 21/01/1964 (Brasil, 1964), que definem como função privativa do psicólogo métodos e técnicas relacionadas ao diagnóstico, orientação e seleção profissional, orientação psicopedagógica e solução de problemas de ajustamento, determinam que, para o funcionamento dos cursos, devem ser organizadas pelas faculdades os Serviços Clínicos e de aplicação à educação e ao trabalho, e orientaram a grade curricular e os campos de estágio em Psicologia Clínica, Escolar e Organizacional.

No período da ditadura militar, durante a qual predominava a ideologia privatista e a ênfase no modelo biomédico, vê-se a rápida expansão dos hospitais psiquiátricos privados, cujos leitos eram contratados pelo Estado e que tomaram grandes proporções. Reforça-se aqui que a expansão da assistência psiquiátrica através da compra dos leitos privados durante o regime militar tinha como foco em um primeiro momento os trabalhadores inseridos no mercado formal e, portanto com cobertura previdenciária, e o quadro nosológico predominante dessas institui- 
ções durante o regime era de neuróticos e alcoolistas (Resende, 1994).

A segunda metade da ditadura militar (1974 1985) foi marcada por sucessivas crises sociais, econômicas e sanitárias, que influenciaram profundamente nas fontes de financiamento da previdência social e no questionamento da resolutividade do modelo de saúde adotado até então, fundado no seguro social, na atenção médica individual, hospitalocêntrica e curativa, em que só os trabalhadores inseridos no mercado formal tinham garantido o direito à assistência médica previdenciária. Aos que não eram cobertos pela assistência previdenciária, continuavam as internações nos grandes asilos, que, diante das críticas da ausência do tratamento médico, começaram a ser questionados e iniciaram-se transferências dos internos asilares para os hospitais psiquiátricos conveniados.

Como enfrentamento à consequente crise previdenciária, que também enfrentava denúncias de fraudes no faturamento das instituições privadas, além das condições precárias de atendimento que fugia do escopo da atenção clínica e de eleições diretas para os governos estaduais, ao mesmo tempo em que diminuíram os recursos destinados à assistência psiquiátrica, iniciam-se experiências inovadoras de atenção à saúde mental fora do contexto hospitalar, que demandavam menos custos públicos. Nesse contexto, e no processo de redemocratização do país, a partir de 1985, iniciam-se experiências que depois serviriam de base para um novo modelo de assistência em saúde mental e de subsídios para a reformulação legislativa e normativa.

No final da década de 1980, o município de Santos implantou um Programa de Saúde Mental com os Núcleos de Atenção Psicossocial, ao mesmo tempo em que realizou intervenção no Hospital Psiquiátrico do município, e em 1987 foi criado o Centro de Atenção Psicossocial (CAPS) Professor Luiz da Rocha Cerqueira, na cidade de São Paulo, que serviu de modelo normativo para a proposta dos novos serviços de saúde mental (Tenório, 2002).

Essas duas experiências tornaram-se referência para a proposta de um novo modelo de assistência em saúde mental no Brasil, com serviços abertos e territorializados, cuja centralidade estava no usuário e suas potencialidades.

No Congresso Nacional, o então deputado Paulo Delgado inicia as discussões de uma Lei da Reforma Psiquiátrica, através do projeto de Lei $\mathrm{n}^{\circ}$ 3.657/1989, que viria a ser promulgado 12 anos depois, como a Lei $\mathrm{n}^{\circ} 10.216 / 2001$, visando a reorientação da aplicação dos recursos públicos para a implantação de serviços substitutivos de saúde mental, fechamento de leitos psiquiátricos e autorização judicial para internações sem o consentimento do usuário ou dos familiares (Brasil, 2004a).

O CAPS tornou-se o serviço central para a organização da rede de atenção em saúde mental na perspectiva da efetivação da Lei $\mathrm{n}^{\circ} 10.216 / 2001$, sendo aberto e substitutivo aos hospitais psiquiátricos, com a finalidade de garantir o atendimento às pessoas portadoras de transtornos severos e persistentes próximo aos locais onde vivem, e objetivando a reabilitação psicossocial destes no contexto onde suas relações se dão (Brasil, 2004b), e também um importante mercado de trabalho para os profissionais da Psicologia.

Esses serviços representam a inversão da lógica assistencial, constituindo-se como abertos, territorializados, em constante processo de reinvenção das práticas ali desenvolvidas, com equipes multidisciplinares, envolvimento da família no processo de cuidar e trabalho com o sujeito de direitos e cidadania ao invés da intervenção exclusivamente na doença, e demandam dos profissionais da Psicologia formados nas diretrizes curriculares vigentes ainda nos moldes na normatização da década de 1960 uma necessária ressignificação da prática profissional e da finalidade do trabalho a ser desenvolvido.

A concepção do Sistema Único de Saúde (SUS) com a conformação dos serviços de saúde de acordo com a realidade local era efetivada através do princípio da descentralização, garantindo aos municípios autonomia para que realizassem o planejamento da gestão (Lei $\mathrm{n}^{\circ}$ 8.080/1990 - Brasil, 1990). Sem poder interferir diretamente na organização local do SUS, o gestor federal induz os municípios à implantação das ações, serviços e programas de saúde que considera prioritário através dos incentivos financeiros. Essa política resultou, muitas vezes, em um planejamento verticalizado, com a implantação do serviço a fim de receber os recursos federais ofertados, independentemente do planejamento local ou do perfil epidemiológico do município (Scarcelli, \& Junqueira, 2011).

Neste contexto político de indução da implantação de políticas de saúde pelo financiamento, como vinha acontecendo em outros municípios de Mato Grosso (Rézio, \& Oliveira, 2010), foi implantado um CAPS no município de São José dos Quatro Marcos.

Este novo serviço, que ampliou o mercado de trabalho para os profissionais da Psicologia, devido 
à capilaridade nos territórios dos CAPS, exigiu que muitos profissionais de saúde reconstruíssem o significado e a finalidade das suas práticas, para além do que é privativo de cada ciência, demandando também novas práticas, de mudança do modelo voltado para o ajustamento dos desviantes, a partir de um conjunto de práticas privativas da Psicologia, como estabelecido no Currículo Mínimo de 1962.

A Psicologia em particular, fortemente relacionada à prática clínica individual na atenção aos processos de adoecimento, deveria dar espaço à uma atuação inovadora, multidisciplinar, de reabilitação psicossocial, relacionada à potência da saúde de cada sujeito, convergentes às mudanças no campo da saúde pública e do sistema de saúde nacional.

Frente a este desafio de não apenas mudar de modelo assistencial, mas de superar este modelo asilar/manicomial, em 2004 ocorreu a aprovação das novas Diretrizes Curriculares Nacionais para os Cursos de Psicologia, que não propunham mudanças efetivas para a formação voltadas para a reabilitação psicossocial em saúde mental (Ribeiro. \& Luzio, 2008), mas traziam alterações significativas na formação instituída até então desde 1962 (Poppe, \& Batista, 2012), substituindo uma formação excessivamente centrada no conteúdo pela proposta de indicar caminhos.

Este artigo não tem por objetivo problematizar o Currículo Mínimo de 1962 ou as novas Diretrizes Curriculares de 2004, no entanto, a experiência relatada relaciona-se com a necessária conformação da atuação profissional de quem havia sido formado a partir do Currículo Mínimo ao novo modelo assistência na saúde pública, que já vinha sendo discutida pela categoria profissional.

Em 2001, na Universidade de Cuiabá, havia um movimento de formação dos docentes para o planejamento de uma nova grade curricular, no contexto das discussões para a construção das novas diretrizes curriculares de 2004, com a inclusão de disciplinas e campo de estágio sobre/na saúde pública. Essas discussões proporcionaram aos docentes uma subversão do currículo, problematizando suas limitações em sala de aula, a partir da construção conjunta dos alunos de uma nova perspectiva da prática da Psicologia.

Ao final da formação e tendo a saúde pública como um campo de atuação profissional almejado, como muitos outros que se formaram ainda no currículo anterior às alterações das diretrizes curriculares na área da saúde (Poppe, \& Batista, 2012), apesar da formação crítica e da compreensão da potência do trabalho do psicólogo na comunidade, para além do modelo de atenção normalizador, havia a sensação de despreparo em relação ao exercício desta prática e do campo de atuação, como relatado por outros profissionais no estudo de Cantele, Arpini e Roso (2012).

Na busca do lugar do psicólogo na comunidade, o CAPS de São José dos Quatro Marcos constitui-se no espaço privilegiado para a promoção da saúde, possibilitada pela ressignificação do que é ser psicólogo, de constante reconstrução das práticas possíveis de reabilitação psicossocial pela potencialização do que os sujeitos tinham de saudável nos espaços da cidade, em um processo de negociação permanente entre gestor, profissionais, usuários e comunidade.

Desta forma, pretende-se com este artigo fomentar a discussão sobre os desafios na reconstrução cotidiana do ser psicólogo, promover saúde mental, reabilitação psicossocial, participação social, entre outros, em um CAPS sem histórico de luta pela melhoria do atendimento psiquiátrico, mas que foi constituindo sua própria história a partir da luta de cada um dos profissionais e usuários a partir do momento que estes tomaram pra si a sua gestão.

O objetivo é relatar a vivencia profissional e as dificuldades colocadas frente os saberes apreendidos no embate cotidiano com as práticas anteriormente existentes no serviço, a formação dos profissionais de saúde da equipe ainda baseada no modelo anterior de assistência que deveria ser superado, a resistência dos usuários da adesão ao novo modelo assistencial e o renascimento de todos estes atores materializado na ressignificação da razão de ser deste serviço substitutivo de saúde mental no interior de Mato Grosso.

\section{Método}

Esta experiência passou-se no período de 2007 a 2009 em um serviço de atenção psicossocial em funcionamento desde 2002, no município de São José dos Quatro Marcos, interior de Mato Grosso, que conta com 19 mil habitantes e faz fronteira com outros municípios pequenos sem assistência em saúde mental.

Em 2007, o CAPS do tipo I funcionava em uma casa alugada no centro da cidade, que possuía jardim; quatro salas, sendo para atendimento individual, apoio administrativo, oficina e reunião; recepção, cozinha, ampla varanda externa e quintal; em uma disposição próxima do estabelecido pela Reforma Psiquiátrica (MS, 2004), e seu horário de funcionamento 
era das 07:00 às 11:00 e das 13:00 às 17:00, de segunda a sexta-feira.

No mesmo ano foi realizado concurso público municipal e formada uma equipe mínima completa de profissionais concursados, sendo psiquiatra, enfermeira, psicóloga, assistente social, pedagoga, técnica de enfermagem, assistente administrativo e auxiliar de serviços gerais. Os oficineiros eram contratados a cada dois anos por processo seletivo, conduzido pela própria equipe, incluindo todos os trâmites, dos critérios a relação de aprovados.

A carga horária da psicóloga no CAPS era de 20 horas e a profissional que me antecedeu realizava atendimentos clínicos individuais e a devida guarda de todo registro destes atendimentos. Com o meu ingresso, ela levou os registros e estabeleci novos instrumentos e atividades a serem desenvolvidas pela Psicologia naquele serviço, registrando as ações no prontuário dos usuários.

Foi realizado acolhimento, avaliação psicológica, observação e atendimento individual com usuários de diagnóstico recente e que não se adequaram às atividades de grupo, norteadas pela formação do estágio em Psicologia clínica na abordagem existencial fenomenológica (Romero, 2001).

Neste artigo, são relatadas as dificuldades encontradas e quais caminhos foram construídos em busca de uma atuação profissional da Psicologia dentro dos princípios da Reforma Sanitária e da Reforma Psiquiátrica.

Em um primeiro momento, foram sintetizadas as experiências mais significativas e emblemáticas através de um relato livre e, posteriormente, o embasamento teórico a partir de outras experiências em serviços de saúde mental corroboraram com a discussão da prática profissional da Psicologia no CAPS. Não foram utilizadas categorias de análise ou teórica para a sistematização deste relato, sendo suas reflexões norteadas pelo desenrolar da experiência na referida unidade de saúde.

\section{Resultado e discussão}

O primeiro impacto ao ter sido comunicada de que o trabalho seria em um serviço de saúde mental, como já descrito por outros profissionais (Cantele et al., 2012), foi de estranhamento em relação ao que se espera de um serviço substitutivo de hospital psiquiátrico.

A loucura dos hospitais era acompanhada da uniformização dos internos, do silêncio e apatia da contenção química através dos medicamentos e da submissão velada em consideração a uma autoridade violenta legitimada pela prática psiquiátrica.

Essa experiência já deveria estar no passado para muitos usuários do serviço, no entanto, neste CAPS em particular, os usuários assíduos eram pessoas com transtornos mentais leves que, em algum momento da vida passaram por uma crise, angústia ou luto que as marcaram profundamente, mas que poderiam se libertar da dependência institucional e farmacológica do CAPS e realizarem o acompanhamento na atenção básica.

Muitos desses usuários frequentavam o serviço desde o início do seu funcionamento, e havia receio da equipe em colocar limites na relação de assistência do serviço, no sentido de reduzir gradativamente a frequência do mesmo até encaminhar para outros espaços da comunidade que lhes oferecesse lazer e convivência, tal qual observado em outro serviço por Mielke, Kantorski, Olschowsky e Jardim (2011).

A desinstitucionalização preconizada pela Reforma ia além da desospitalização e o fato dos usuários estarem recebendo atenção de serviços abertos não era empecilho para desenvolverem dependência em relação aos profissionais e ao serviço em si, mantendo poucos vínculos aos quais se filiavam e restringiam a rotina às atividades institucionais (Sales, \& Dimenstein, 2009).

Apesar das portas e portões abertos, era como se no CAPS as pessoas que o frequentavam até então também desenvolvessem nova cronicidade (Pande, \& Amarante, 2011), organizando sua rotina em torno da instituição, desenvolvendo atividades que poderiam ser realizadas em outros serviços públicos de saúde e de assistência social, limitando seu percurso pela cidade e suas relações interpessoais.

A prática deveria ser pensada para além do CAPS, na busca de alternativas que tornassem esse serviço substitutivo dispensável, com suas ações "diluídas" nos outros serviços da rede de atenção à saúde.

Por outro lado, as pessoas portadoras de transtornos mentais severos e persistentes frequentavam $o$ serviço para atualização de receita médica e encaminhamento para internação no antigo hospital psiquiátrico do estado, atual Centro Integrado de Atenção Psicossocial, constituído na mesma estrutura física.

Mas como, se o tratamento delas era a razão de existir do CAPS e o encaminhamento para tratamento em unidade fechada, longe do território e com restrição de liberdade, era o indício de que o serviço não estava dando conta da sua finalidade (Brasil, 2004b). 
Era necessário realizar dois movimentos: trazer para o serviço e vincular a equipe aos usuários portadores de transtornos severos e persistentes, egressos de longa internação, e que na avaliação multidisciplinar da equipe, em discussão de estudo de caso e de comum acordo com o usuário, concluía-se pela necessidade da frequência no serviço; e, ao mesmo tempo, ao frequentar o serviço, apoiá-los na busca de outros espaços comunitários, a fim de aumentar sua rede de apoio e vinculação.

A luta ali seria então de destruir os muros do CAPS e da instituição que aprisiona mesmo com os portões abertos e ocupar outros espaços comunitários que não fossem exclusivos para os usuários do serviço, mas que atendessem suas demandas referentes às outras questões que os atingiam da mesma forma que os que não tem diagnóstico de transtorno mental.

Observava-se em alguns profissionais da equipe a necessidade de ampliação do olhar sobre as pessoas portadoras de transtornos mentais severos e persistentes para além do paradigma biomédico, para que o trabalho com elas deixasse de ser exclusivamente relacionado à doença e de que o lugar da manifestação da doença era no hospital. A predominância deste paradigma, como já analisado em outro serviço (Antunes, \& Queiroz, 2007), denota a hegemonia do saber médico, e da atuação dos outros profissionais de acordo com as demandas encaminhadas por este profissional.

Mais do que o tratamento/controle da doença neste paradigma, era necessário pensar a perspectiva do cuidado e da reabilitação psicossocial, a ampliação das relações pelo que os usuários ainda possuíam de saudável sem deixar de considerar os impactos que a doença geravam na sua vida e a utilização das mais variadas estratégias terapêuticas para que a vida desses sujeitos se desenrolasse em outros espaços comunitários.

Em outro estudo (Nunes, Torrenté, Ottoni, Moraes Neto, \& Santana, 2008), também é possível observar como a resistência de profissionais da equipe em relação às concepções norteadoras das práticas pode reproduzir ações que mantém os usuários institucionalizados, ainda que em um serviço aberto como o CAPS e, para a superação disso, faz-se necessário primeiramente um movimento de dentro para fora, de ressignificação do serviço e da função de cada um nesse espaço.

Na perspectiva da reabilitação psicossocial, o cuidado ofertado no CAPS deveria ser cotidianamente reinventado, com foco nas necessidades do usuário, convocado a ser protagonista da sua própria história e a começar pelo próprio tratamento (Babinski, \& Hirdes, 2004).

A prática do profissional psicólogo em específico ainda era fortemente marcada pelo que Dimenstein (2000) aponta como uma cultura profissional de prática clínica individual para ajustamento dos pacientes à sociedade, quando o CAPS suscitava a reintegração destas pessoas ao convívio comunitário não por este ajustamento, mas por sua singularidade.

Existia um estranhamento em pensar outras atividades para além do atendimento individual, caracterizado pela atuação da psicóloga anterior, ainda que o sigilo preservasse os usuários e a própria equipe sem conhecimento do conteúdo, resultados e conclusões do trabalho psicológico desenvolvido.

Em depoimento (Pinheiro, \& Mayo, 1985), psicólogas que atuaram em serviços comunitários de saúde descrevem a limitação dos atendimentos nos moldes de consultórios individuais nesses tipos de serviço e a necessária experimentação em busca da construção coletiva de uma prática que atenda as necessidades em saúde dos usuários.

Na elaboração pela equipe do Projeto Terapêutico Global (PTG) da instituição, no qual seriam descritas todas as atividades a serem desenvolvidas no CAPS, primeiro retomamos a história da luta antimanicomial no Brasil e o por quê da criação deste serviço em detrimento do funcionamento dos hospitais psiquiátricos.

Confrontou-se a prática institucional com o arcabouço teórico que definia quais usuários deveriam ser beneficiários daquele serviço e as diretrizes para as intervenções a serem realizadas, e foi necessário a construção de um PTG que não reproduzisse nem o que vinha sendo feito até então nem as teorias descontextualizadas.

$\mathrm{Na}$ (re)construção da finalidade do serviço, novas formas de fazer saúde mental foram surgindo, como possibilidades de intervenção em reabilitação psicossocial, e passíveis de se reinventarem de acordo com os feedbacks nas interações com os usuários e familiares.

O PTS elaborado pela equipe era discutido com o usuário e, caso ele concordasse ou fizesse modificações, era feito um contrato de tratamento, que teria a validade de três meses, período após o qual era realizada a revisão do referido projeto, cujo objetivo principal era reduzir gradativamente a frequência no CAPS e inserir o usuário em outros dispositivos comunitários de atenção. 
Outro espaço que também foi se instituindo como formação para a Reforma Psiquiátrica e de novas proposições sobre as práticas foram as assembleias de profissionais, usuários e familiares. Apesar de um início com baixa adesão dos usuários, um plebiscito para escolha do nome do CAPS os mobilizou de tal forma que a participação na assembleia se tornou obrigatória para muitos que se corresponsabilizaram pela gestão do serviço cujo nome eles haviam escolhido.

As oficinas terapêuticas de geração de renda eram espaços de troca intensa tanto entre a oficineira e os usuários, quanto entre os usuários, e eu circulava por estas oficinas com o ouvido atento observando novas formas de ser daquele usuário no mesmo espaço institucional.

As oficinas que coordenei, a exemplo do que foi verificado por Nunes, Torres e Zanotti (2015), tinham por finalidade a expressão da subjetividade, para escutá-los no que ainda permanecia de íntegro na sua consciência, e de que forma eles interpretavam o conteúdo dos sintomas.

Uma oficina que propus no CAPS foi a de cinema, baseada em um projeto que conheci em Porto Alegre intitulada “Cinema em Debate” (Rainone, \& Froemming, 2008), com adaptações para a nossa realidade local.

Foi selecionada uma relação de filmes com personagens centrais ou secundários que abordavam algum aspecto sobre transtornos mentais, para fomentar a discussão da forma como os sintomas se davam naqueles personagens, a repercussão que o transtorno mental trazia para a vida deles de uma forma geral e o que faziam para superar as dificuldades em relação à convivência com os outros.

Devidamente divulgado, a expectativa de adesão era grande, mas ninguém quis participar da atividade. Uma estratégia adotada foi trocar o lugar, pois tal qual relatado por Rainone e Froemming (2008), o próprio deslocamento para outro espaço que não o característico do tratamento já era uma forma de fomentar a incursão desse sujeito pelo território, e na ausência de um cinema no município, improvisamos uma estrutura no centro comunitário localizado também na região central, e o convite foi estendido para a comunidade em geral, porém ainda assim a adesão foi baixa.

Ao pesquisar entre os usuários por que a oficina não deu certo, foi relatado que os filmes não haviam despertado interesse por se tratarem de discussão sobre a doença, e naquele momento, eles queriam vivenciar as questões do cotidiano, conflitos e problemas que surgiam na relação com o outro.
Foi colocada uma caixa de sugestão e os filmes escolhidos pelos usuários eram predominantemente animações em que algum personagem tinha alguma diferença, ou problema familiar. As discussões, aparentemente banais por se tratarem de filmes infantis, ganhavam um contorno de carne e osso, quando os usuários relatavam as próprias experiências que os fizeram se sentir naquela condição do personagem principal.

Observamos que as festas e confraternizações, muitas vezes mais que as oficinas, mobilizavam equipe e usuários desde a concepção, planejamento, organização até a limpeza do local, e todas as atividades do serviço se voltavam para o tema dos eventos de forma transversal, sendo sempre de grande participação, tal qual relatado em outro CAPS por Wetzel, Kantorski e Souza (2008).

As festividades representavam a conexão do serviço com o mundo de fora, através das celebrações das datas do calendário tal qual a tantos outros dispositivos comunitários, sem relação específica com o universo da saúde mental, e a presença de familiares e amigos dos usuários e dos profissionais se dava para um momento de descontração e alegria.

O familiar, que anteriormente se dirigia ao CAPS para lamentar situações vividas com o usuário ou que era chamado ao serviço para ouvir queixas começou a frequentar e a se vincular com o serviço, os profissionais e seus entes também para momentos de alegria, de vivências agradáveis e de reconhecimento das potencialidades do sujeito que não é só a doença e problemas, mas também é ativo e transformador.

O evento mais significativo para marcar a transição de um serviço de atendimento psiquiátrico para a proposta da política de implantação do CAPS de reabilitação social foi o de comemoração da Luta Antimanicomial, evento do calendário anual dos serviços de saúde mental que teve origem a partir da Articulação Nacional da Luta Antimanicomial, fundada no documento "Manifesto de Bauru", produto final do II Congresso do Movimento dos Trabalhadores da Saúde Mental em 18/05/1987 (Lüchmann, \& Rodrigues, 2007).

Todos os anos neste mesmo dia e mês são realizados eventos para relembrar o percurso histórico que nos conduziu à atual conformação dos serviços de saúde mental ofertados pelo poder público, e no município de São José dos Quatro Marcos, em comemoração a esta data, foram realizadas atividades em dois dias, sendo no primeiro um dia inteiro de atividades, incluindo desfile na avenida principal entoado por 
palavras de ordem contra o tratamento em unidade fechada, palestras sobre o funcionamento de CAPS na capital Cuiabá e na cidade de Várzea Grande, mesas redondas, vídeos, música ao vivo e lanche aberto para usuários, profissionais, familiares, amigos, acadêmicos de cursos de saúde da faculdade do município, profissionais de outros serviços, autoridades do poder executivo e legislativo municipal, e demais participantes.

Foram exibidos através de vídeos relatos de personalidades da cidade sobre como administravam a própria loucura, de como os usuários do serviço percebiam a atuação dos profissionais da unidade encenando um dia no CAPS em que eles eram os profissionais e quais as diferenças na atenção à saúde mental antes e depois dos CAPS relatados por quem vivenciou os dois tratamentos.

A mesa-redonda contou com a participação de profissionais, secretária de saúde, usuário e familiar e debateu as dificuldades que atravessavam a atenção à saúde, e que extrapolavam a governabilidade do serviço, mas que dependiam de um debate com a sociedade, dentre outras atividades do evento.

No segundo dia, foi realizado um baile só para os profissionais e usuários do CAPS e seus familiares no Centro de Convivência dos Idosos do município, onde foi comemorado o Dia da Luta Antimanicomial em São José dos Quatro Marcos.

Foi nesse dia que vivemos todos nós pela primeira vez a luta que motivou a criação deste serviço, que deve ele também tal como os hospitais psiquiátricos, um dia se tornarem prescindíveis, substituídos por centros de cultura e/ou outros dispositivos comunitários não exclusivos aos usuários com transtorno mental severo e persistente, mas aberto a toda comunidade.

A luta pelo fim dos hospitais psiquiátricos é primeiramente uma luta pela desinstitucionalização desses sujeitos, e a reabilitação psicossocial não preconiza a independência, mas a dependência de um maior número de pessoas, e que se deve buscar a autonomia, caracterizada pela capacidade das pessoas de redigir normas para a própria vida (Pereira, 2007).

No CAPS, estabeleciam-se relações de dependência dos usuários com os profissionais de referência em que confiavam seus sofrimentos e suas alegrias. No entanto, a atenção em saúde fora do hospital psiquiátrico, na perspectiva da reabilitação psicossocial, não se passava toda no CAPS, e através do acompanhamento terapêutico, era possível emprestar aos nossos usuários o poder de troca que se encontrava nulo devido ao preconceito das outras pessoas em relação ao transtorno mental.
Diferentemente do hospital psiquiátrico, no CAPS a desinstitucionalização se dá também no âmbito do poder, antes centrado no psiquiatra e tendo o usuário seu discurso e pensamento poder zero, e agora deve ser deslocado da equipe para o usuário, em um processo de troca a fim do mesmo ser capaz por si só de estabelecer contratos de relação (Nardi, \& Ramminger, 2007).

Com vários usuários com comorbidade clínica, como diabetes, obesidade e hipertensão, foi acordado que a equipe buscaria os ingredientes do lanche da manhã e da tarde para que fosse mais saudável diretamente no mercado, e essa simples ida ao mercado acabou se tornando uma oficina também.

Os usuários do serviço, quando iam ao mercado, já ligavam o alerta de todos, à espera de alguma situação inusitada, no entanto, quando iam com um profissional do CAPS, estes emprestavam seu poder de troca social, ao mesmo tempo que os usuários escolhiam os itens para serem comprados. Em um outro momento que retornavam ao estabelecimento, havia ainda a lembrança de que na ida com o profissional do CAPS tinha sido tudo bem, até tinham ajudado, e que não deveriam tomar maiores atenções.

No mercado e em tantos outros espaços quanto nos era possível, nós realizávamos o acompanhamento, emprestando o poder de troca e auxiliando nos processos de contratualidade com os outros que não eram do serviço de saúde ou familiares, em busca da almejada reabilitação psicossocial.

\section{Considerações finais}

Diante do enfrentamento da prática profissional, a partir daquilo que se aprendeu na formação ainda deficiente naquele momento para as novas conformações históricas dos serviços de saúde, foi preciso reinventar cotidianamente a si mesmo e a expectativa em relação aos impactos que se busca efetivar junto aos usuários, ao serviço e à comunidade na qual ele está inserido.

As dificuldades encontradas são constituintes de um longo processo de transformação da prática da Psicologia para se entranhar na Saúde Pública com toda a potência possível (Pinheiro, \& Mayo, 1985).

Há também os embates entre as concepções e vivências dos outros profissionais de diferentes formações envolvidos na equipe, e até mesmo dos outros dispositivos comunitários que foram utilizados como terapêuticos para os usuários, e a necessidade de se sair de uma zona de conforto do atendimento psiquiátrico já pré-estabelecido, com atuações definidas. 
Para um serviço como o CAPS, era necessária a invenção de novas práticas, o que demandou, além dos conhecimentos prévios, também o que Ramminger e Brito (2011) colocam como "uso exacerbado de si", já que se configurava como um serviço novo em que a construção das práticas voltadas para o cuidado e não para a doença deve ser cotidiana e o vazio de normas prévias dificultava ainda mais o abandono das rotinas já estabelecidas para as mudanças provocadas a partir do ingresso dos novos profissionais concursados.

Ainda assim, a Reforma Psiquiátrica que vivemos, construída de dentro do serviço para fora, além de humanizar o atendimento, também devolveu a vida ainda que com altos e baixos, mas sempre em movimento, a tantas pessoas que se encontravam esquecidas não só pelos familiares e pela sociedade, mas de si mesmas, sem saber mais quem elas eram, do que gostavam, do que desejavam e do que sonhavam, para além do diagnóstico e do tratamento.

A institucionalização dos corpos e da alma, o abandono em espaços estéreis, os discursos desconectados proferidos sem escuta, o sentimento embotado, a agressividade e o vazio do olhar ficaram no passado para vários usuários do CAPS egressos de longa internação, mas ao mesmo tempo, nessa nova realidade, eles pareciam igualmente marginalizados, com o diagnóstico como mote principal das relações que estabeleciam com os serviços de saúde e a comunidade de uma forma geral.

A ocupação do CAPS por seus usuários não só proporcionou à equipe, mas principalmente a eles mesmos, o estabelecimento de um vínculo pela potência de saúde que sobreviveu a todo tipo de assujeitamento que eles passaram, e até mesmo um espaço para dar vazão aos delírios e alucinações como produção de subjetividade, ao invés de dopá-los junto com os seus possíveis significados.

E a vida do CAPS, de tranquila e organizada quando habitada pelos usuários de transtornos leves, passou a ser de constante reorganização pelos profissionais e usuários de transtornos severos e persistentes, porque a desconstrução do que estava posto até então era sempre necessária para o reestabelecimento de novas formas de se vincular e se organizar os problemas inerentes de se relacionar com o outro.

Além dos desafios profissionais na atuação propriamente dita, a interiorização da Psicologia, com a abertura de serviços especializados em cidades pequenas, de até 20 mil habitantes, contribuiu para a migração destes profissionais de seus domicílios de residência para outros municípios, muitas vezes sem rede de atenção à saúde estabelecida e profissionais experientes para supervisão clínica e institucional.

Apesar de ter me direcionado para outros desafios da formação e atuação no SUS, tenho convicção da profunda transformação que esta experiência trouxe para a minha prática profissional, ao deixar a doença mental em segundo plano e olhar para o sujeito de potencialidade de ordenamento de um serviço, poder acompanhá-lo em seu caminhar pelo território e de afetar e me deixar ser afetada.

As atividades terapêuticas ofertadas no CAPS eram de vivência, da realização da experiência daquilo que se traçava como objetivo, com as questões sendo trabalhadas no contexto que elas se davam e, além de profissional, muitas vezes, eu também me tornava usuária deste serviço, na medida em que também era cuidada e tinha minhas questões trabalhadas na experiência singular que era a interação com aquela coletividade.

A continuação da trajetória no SUS e, também, o processo de formação invertendo a lógica dominante no mercado da especialização serviram para a ampliação das minhas potenciais práticas, voltadas não para um fazer da Psicologia privativa desta ciência, mas para as necessidades em saúde do sujeito histórico que é determinado socialmente.

\section{Referências}

Antunes,S.M.M.D.O.,\&Queiroz,M.D.S.(2007).AconfiguraçãodareformapsiquiátricaemcontextolocalnoBrasil:uma análisequalitativa. CadernosdeSaúdePública, 23(1),207-215.https://doi.org/10.1590/S0102-311X2007000100022

Babinski, T., \& Hirdes, A. (2004). Reabilitação psicossocial: a perspectiva de profissionais de centros de atenção psicossocial do Rio Grande do Sul. Texto \& Contexto - Enfermagem, 13(4), 568-576. https://doi.org/10.1590/S0104-07072004000400009

Brasil. (1964, 24 de janeiro). Decreto № 53.464, de 21 de janeiro de 1964. Regulamenta a Lei n. ${ }^{\circ}$ 4.119, de 27 de agosto de 1962, que dispõe sobre a profissão de psicólogo. Diário Oficial da União.

Brasil (2004a). Legislação em saúde mental: 1990 - 2004 (5a ed.). Brasília, DF: Ministério da Saúde, 2004. 
Brasil. (1990, 20 de setembro). Lei № 8.080, de 19 de setembro de 1990. Dispõe sobre as condições para a promoção, proteção e recuperação da saúde, a organização e o funcionamento dos serviços correspondentes e dá outras providências. Diário Oficial de União.

Brasil. (1962, 5 de setembro). Lei № 4.119, de 27 de agosto de 1962. Dispõe sobre os cursos de formação em psicologia e regulamenta a profissão de psicólogo. Diário Oficial de União.

Brasil. Ministério da Saúde. (2004b). Saúde mental no SUS: os centros de atenção psicossocial. Brasília, DF: o autor. Recuperado de http://www.ccs.saude.gov.br/saude_mental/pdf/sm_sus.pdf

Cantele, J., Arpini, D. M., \& Roso, A. (2012). A Psicologia no modelo atual de atenção em saúde mental. Psicologia: Ciência e Profissão, 32(4), 910-925. https://doi.org/10.1590/S1414-98932012000400011

Dimenstein, M. (2000). A cultura profissional do psicólogo e o ideário individualista: implicações para a prática no campo da assistência pública à saúde. Estudos de Psicologia (Natal), 5(1), 95-121. https://doi.org/10.1590/S1413-294X2000000100006

Lüchmann, L. H. H., \& Rodrigues, J. (2007). O movimento antimanicomial no Brasil. Ciência \& Saúde Coletiva, 12(2), 399-407. https://doi.org/10.1590/S1413-81232007000200016

Mielke, F. B., Kantorski, L. P., Olschowsky, A., \& Jardim, V. M. D. R. (2011). Características do cuidado em saúde mental em um CAPS na perspectiva dos profissionais. Trabalho, Educação \& Saúde, 9(2) 265-276. https://doi.org/10.1590/S1981-77462011000200006.

Nardi, H. C., \& Ramminger, T. (2007). Modos de subjetivação dos trabalhadores de saúde mental em tempos de Reforma Psiquiátrica. Physis, 17(2), 265-287. https://doi.org/10.1590/S0103-73312007000200004

Nunes, M., Torrenté, M. D., Ottoni, V., Moraes Neto, V., \& Santana, M. (2008). A dinâmica do cuidado em saúde mental: signos, significados e práticas de profissionais em um Centro de Assistência Psicossocial em Salvador, Bahia, Brasil. Cadernos de Saúde Pública, 24(1), 188-196. https://doi.org/10.1590/S0102-311X2008000100019

Nunes, V. S., Torres, M. D. A., \& Zanotti, S. V. (2015). O psicólogo no caps: um estudo sobre oficinas terapêuticas. ECOS-Estudos Contemporâneos da Subjetividade, 5(2), 135-146. Recuperado de http://www.periodicoshumanas. uff.br/index.php/ecos/article/view/1649

Pande, M. N. R., \& Amarante, P. D. C. (2011). Desafios para os Centros de Atenção Psicossocial como serviços substitutivos: a nova cronicidade em questão. Ciência \& Saúde Coletiva, 16(4), 2067-2076. https://doi.org/10.1590/S1413-81232011000400006

Pereira, M. A. O. (2007). A reabilitação psicossocial no atendimento em saúde mental: estratégias em construção. Revista Latino-Americana de Enfermagem, 15(4), 658-664. https://doi.org/10.1590/S0104-11692007000400021

Pinheiro, O. G., \& Mayo, G. V (1985). Enfrentando desafios em Saúde Mental. Psicologia: Ciência e Profissão, 5(2): 6-10. https://doi.org/10.1590/S1414-98931985000200003

Poppe, A. R. S., \& Batista, S. H. S. D. S. (2012). Formação em psicologia no contexto das diretrizes curriculares nacionais: uma discussão sobre os cenários da prática em saúde. Psicologia Ciência e Profissão, 32(4), 986-999. https://doi.org/10.1590/S1414-98932012000400016

Rainone, F., \& Froemming, L. S. (2008). As potencialidades das imagens cinematográficas para o campo da atenção em saúde mental. Latin American Journal of Fundamental Psychopathology On Line, 5(1), 69-83. Recuperado de http://pepsic.bvsalud.org/scielo.php?script=sci_arttext\&pid=S1677-03582008000100007\#1

Ramminger, T., \& Brito, J. C. (2011). "Cada Caps é um Caps": uma coanálise dos recursos, meios e normas presentes nas atividades dos trabalhadores de saúde mental. Psicologia \& Sociedade, 23(n ${ }^{\circ}$ spe): 150-160. https://doi.org/10.1590/S0102-71822011000400018

Resende, H. (1994). Política de saúde mental no Brasil: uma visão histórica. In: S. A. Tundis, \& N. R. Costa, Políticas de saúde mental no Brasil (pp. 15-73). Petrópolis, RJ: Vozes.

Rézio, L. D. A., \& Oliveira, A. G. B. D. (2010). Equipes e condições de trabalho nos centros de atenção psicossocial em Mato Grosso. Escola Anna Nery, 14(2), 346-354. https://doi.org/10.1590/S1414-81452010000200019

Ribeiro, S.L., \& Luzio, C. A., (2008). As diretrizes curriculares e a formação do psicólogo para a saúde mental. Psicologia em Revista, 14(2), 203-220. Recuperado de http://pepsic.bvsalud.org/scielo.php?script=sci_arttext\&pi$\mathrm{d}=\mathrm{S} 1677-11682008000200013 \& \operatorname{lng}=\mathrm{pt} \& \mathrm{nrm}=\mathrm{isso}$

Romero, E. (2001). As dimensões da vida humana: existência e experiência. São José dos Campos, SP: Della Bídia. 
Sales, A. L. L. D. F, \& Dimenstein, M. (2009). Psicologia e modos de trabalho no contexto da reforma psiquiátrica. Psicologia: Ciência e Profissão, 29(4), 812. https://doi.org/10.1590/S1414-98932009000400012

Scarcelli, I. R., \& Junqueira, V. (2011). O SUS como desafio para a formação em Psicologia. Psicologia: Ciência e Profissão, 31(2), 340-357. https://doi.org/10.1590/S1414-98932011000200011

Tenório, F. (2002). A reforma psiquiátrica brasileira, da década de 1980 aos dias atuais: história e conceitos. História, Ciências, Saúde. Manguinhos, 9(1), 25-59. https://doi.org/10.1590/S0104-59702002000100003

Wetzel, C., Kantorski, L. P., \& Souza, J. D. (2008). Centro de Atenção Psicossocial: trajetória, organização e funcionamento. Revista Enfermagem Uerj, 16(1): 39-45. http://www.lume.ufrgs.br/bitstream/handle/10183/107164/000660593.pdf?sequence=1

\section{Virgínia de Albuquerque Mota}

Graduada em Psicologia (Universidade de Cuiabá), especialista em Epidemiologia (Universidade Federal de Goiás) e Gestão do Trabalho e Educação em Saúde (Universidade Federal do Rio Grande do Norte) e mestre em Saúde Coletiva (Universidade Federal de Mato Grosso). Atuou como Psicóloga no Centro de Atenção Psicossocial em São José dos Quatro Marcos e Professora Substituta do Departamento de Saúde Coletiva na Universidade Federal de Mato Grosso. Está há 7 anos como Psicóloga na Seção de Auditoria do Ministério da Saúde em Mato Grosso. E-mail: virginia.a.mota@gmail.com

\section{Ilze Maria Gonçalves da Costa}

Possui graduação em Psicologia pela Universidade de Cuiabá (1998), graduação em Serviço Social pela Universidade Federal de Mato Grosso (1978). Atuou como Assistente Social na Universidade Federal de Mato Grosso e na Universidade Federal de Rondônia. Atualmente é Professora e Supervisora de estágios da Universidade de Cuiabá, e Psicóloga Clínica, com atuação em Orientação Profissional.. E-mail: ilze.maria@terra.com.br

Endereço para envio de correspondência:

Rua Clarindo Epifanio da Silva, n. ${ }^{\circ} 1015$ Casa 18 Quadra 01. Despraiado. CEP: 78048-004.

Cuiabá - MT, Brasil.

Recebido $24 / 11 / 2016$

Reformulado 10/07/2017

Aprovado 02/08/2017

Received $11 / 24 / 2016$

Reformulated $07 / 10 / 2017$

Approved 02/08/2017

Recebido $24 / 11 / 2016$

Reformulado 10/07/2017

Aceptado 02/08/2017

Como citar: Mota, V. A., \& Costa, I. M. G. (2017). Relato de experiência de uma Psicóloga em um CAPS, Mato Grosso, Brasil. Psicologia: Ciência e Profissão, 37(3), 831-841. https://doi.org/10.1590/1982-3703004292016

How to cite: Mota, V. A., \& Costa, I. M. G. (2017). Experience report of a psychologist at a CAPS, Mato Grosso, Brazil. Psicologia: Ciência e Profissão, 37(3), 831-841. https://doi.org/10.1590/1982-3703004292016

Cómo citar: Mota, V. A., \& Costa, I. M. G. (2017). Relato de experiencia de una psicóloga en un CAPS, Mato Grosso, Brasil. Psicologia: Ciência e Profissão, 37(3), 831-841. https://doi.org/10.1590/1982-3703004292016 